\title{
Public opinion surveys of consumers for manner of labeling the food product in the Republic of Macedonia
}

\author{
Gjore Nakov ${ }^{1}$, Nastia Ivanova ${ }^{1}$, Stanka Damyanova ${ }^{1}$, \\ Viktorija Stamatovska ${ }^{2}$, Ljupka Necinova ${ }^{3}$
}

1 - Department of Biotechnology and Food Technologies, University of Ruse

"Angel Kanchev", Branch Razgrad, Bulgaria

2 - University "Ss. Kliment Ohdirski" of Bitola, Technical-technology faculty

Veles, Republic Macedonia

3 - Healthy Food by Zegin, DOO Zegin, Skopje, Republic of Macedonia

Keywords:

Labeling

Food

Consumer

Survey

Macedonia

Article history:

Received 7.12.2016

Received in revised form

23.03.2017

Accepted 30.03.2017

Corresponding author:

Gjore Nakov

E-mail:

gore_nakov@hotmail.com

DOI: $10.24263 / 2304-$

974X-2017-6-1-17

\section{Abstract}

Introduction. The consumer should be informed about the quality and characteristics of the food product that wants to buy, and that is possible only if the product is properly labeled. We conducted a study to examine the opinion of the consumers for the manner of labeling the food in Republic of Macedonia.

Materials and Methods. The review is realized with electronic surveys of 200 people from 13 different cities in Macedonia. Interviewees are divided into five groups according to age: under 19 years, 19-25 years, 26-32 years, $33-50$ years and over 50 years.

Results and discussion. When choosing the right foodstuff majority of respondents, regardless of age read labels that marked products. Another problem emphasizes the use of many numbers and signs with unknown relevance to them, as well as "E" mark on the packaging. For all respondents, the shelf life of the product has more influence in selecting the products that they buy than the product cost. The energy value of the products and the content of salts in them, were not really important when choosing a product. All respondents agree that if the food product contains components that could endanger the human health, it should be properly labeled. Respondents believe that it would be better if the label by which the product is labeled, emphasize the intended customer group.

Conclusion. Consumers when choosing a food product they want to buy most often read the label with which the products are marked. For respondents of great importance is the existence on the product of an information for which group are those products intended to be spend. At the same time it is important to increase the awareness of the consumers about the importance of numbers, symbols and labels, which they meet on the labeling of food products. 


\section{Introduction}

In the last decade Consumer's attitudes towards the nutritional aspect of the foods and proper eating habits are increasing rapidly. Therefore, consumers' are more concern about balance and healthier diet. Further they are becoming more demanding about nutritional information, safe and quality food [1]. Everyone's health depends very much on healthy eating, with a diet consistent with the nutritional needs of everyone [2]. Nutrition information on food labels is an important source of nutrition information but is typically underutilized by consumers [3].

Urbanization has led to a dramatic shift in the food con-sumption patterns around the world. It has increased the availability of unhealthy food, which contribute substantially as a risk factor to the pandemic of non-communicable diseases (NCDs) along with other life style related risk factors such as physical inactivity, consump-tion of alcohol and smoking. Though seen mostly duringadult life, diet-related NCDs result from unhealthy diet-ary practices acquired since childhood. Therefore,healthy eating behaviour should be established early in life as a strategy to prevent NCDs [4].

Label is the most important thing when you want to buy food. When deciding which foods to buy information to labels about nutrition and health it may not be clear to many consumers. What was the best choice for healthiest? The purpose of this study is to analyses consumer's understanding and used of nutrition labels from food products [5].

The labeling of food is an important information for consumers through which they can make their own choice of products depending on their health status, age, physical activity, religious beliefs. "Food" means any substance or product processed, partially processed or unprocessed and intended to or be expected to be consumed for human consumption [6].

Quality labels guarantee compliance not only with current standards, but also with additional quality criteria determined in a corresponding certification system [7].

Sadílek T., System of quality labels in the European Union, Ukrainian Food Journal. 2016. Volume 5. Issue 3, 579-587.

Food quality on the market depends of several factors that are found step by step from manufacturing flow to the development phases of the agro-foodstuffs status. Food labeling is a way of communication that characterizes the quality of the food elements. The information transfer from the label to the consumer is made after purchasing the food product, and usually consumers read the labels from the food products packaging only after they bought the product home [8].

Dumitru Mnerie, Liviu Gaceu, Oleksii Gubenia, Mark Shamtsyan, Adriana Birca, Gabriela Victoria Mnerie (2016), Comparative study on the evolution of the food labeling quality in some countries from the Black Sea region, Journal of Hygienic Engineering and Design, 14, pp. 60-65.

Obligations for marking which the producers and food distributors have, are regulated by the Law on Food Safety and bylaws arising from it. Mandatory requirements for labeling of food are given in the Rulebook on food labeling [9]. Additional requirements for tags that are defined depending on the category of food are prescribed by the regulations for specific security requirements or regulations for quality of certain foods / food product.

By the Agency for Food and Veterinary of Republic of Macedonia is made a guidance in order to provide guidelines to operators with food, about the way of presenting food information to consumers in accordance with the applicable rules in the European Union [10].

By applying the provisions of the Rulebook on labeling of the food: 
- consumer receives all the necessary information's about the composition (listed in descending order according to the proportion of the ingredients in the final product), storage and use of food, expiration date, net weight or volume of the food and more;

- marking must be clearly visible, understandable and easy to read;

- allergens should always be clearly specified on the label;

- is not allowed food labeling which suggests the healing properties of the food;

- food operators may indicate additional data on the tag, if they are accurate and do not cause consumer deception;

- the food must be marked in Macedonian language, it can be marked in other languages as well, but only in addition to marking in Macedonian language [11]. Food operators, despite the data listed above, are obliged to mark the food with information which are determined in accordance with the specific requirements of certain types of food.

The obligation of the buyer is to read the marking before buying the product. If the consumer carefully read the labeling, one can find out more about the ingredients contained in the foodstuff that he wants to buy and thus decide whether the product meets his requirements.

With this paper we wanted to determine whether consumers in Macedonia are satisfied with the way of labeling the food products and what problems they face when choosing a food product that they want to buy.

\section{Materials and methods}

Consumer's opinion is determined based on the answers given to the questions of a questionnaire, which was online. On some of the questions were offered several answers and for each answer respondents should answer "Yes" or "No" (Figure 2, 3, 5 and 6).

The survey was voluntary filled by 200 people from 13 different cities in R. Macedonia: Berovo (1), Bitola (4), Valandovo (1), Veles (102), Kichevo (1), Kumanovo (1), Makedonski brod (3), Prilep (3), Radovish (1), Sveti Nikole (2), Skopje (78), Tetovo (2) and Shtip (1). From the surveyed,63 were men (31.5\%) and 137 women $(68.5 \%)$. Respondents were divided into five groups according to age, under 19 years (8), from 19-25 years (71), from 26-32 years (61), 33-50 years of age (49) and over 50 years (11).

The obtained results of the survey were presented, analyzed and processed using the program Microsoft Excel from the program package Microsoft Office. Each question is specifically analyzed and discussed.

\section{Results and discussion}

The first analysis are based on the respondents who choose food products in the markets. From the determined answers it can be concluded that most of the respondents read the product labels and on basis of that they choose the product, indicating that the labeling of food products is important for consumers (Figure 1). "I read the labels of products" replied $40.85 \%$ of respondents aged between $19-25$ years, $50.82 \%$ of respondents aged between $26-32$ years, $42.83 \%$ of respondents aged between $33-50$ years $27.27 \%$ of respondents aged over 50 years. 


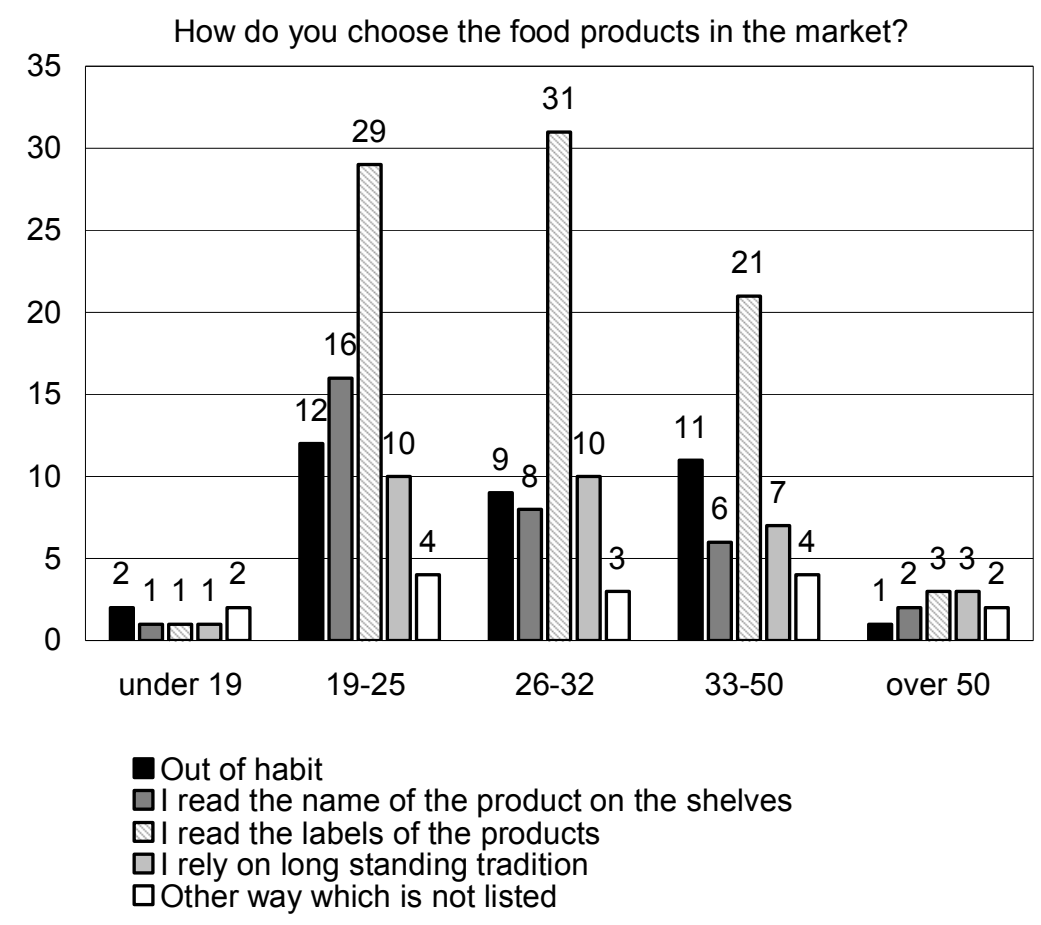

Figure 1. How do you choose the food products in the market?

Alibabic et al. (2012) investigate the extent to which these laws and the regulation are implemented, the results showed that consumers are mostly interested in the data concerning the turation of its shelf live, and $62 \%$ of consumers always chekerd this information [12]. Regarding the question: "Which of the listed difficulties do you meet?" it has been Offered a few answers and for each response respondents had to answers by "Yes" or "No". The Figure 2 shows the only the answer "Yes". From the graphics display it can be concluded that the respondents in the age group below 19 years have difficulties with the small fund, but it should not be ignored other difficulties. Persons from 19-25 years of age with most "Yes" answers stated for small fund and usage of many numbers and signs of unknown significance (with "Yes" replied 46 out of 71 respondents). The persons from 26-33 years and from 33 to 50 years reported to have major difficulties with the small fund (with "Yes" replied 44 out of 61 respondents and 42 out of 49 respondents, respectively). The persons over the age of 50, despite the very small fund and numerous figures and characters (with "Yes" answers replied 10 out of 11 respondents), have problems with the fact that "the information is vague and not readable" (with "Yes" replied 9 out of 11 respondents). 


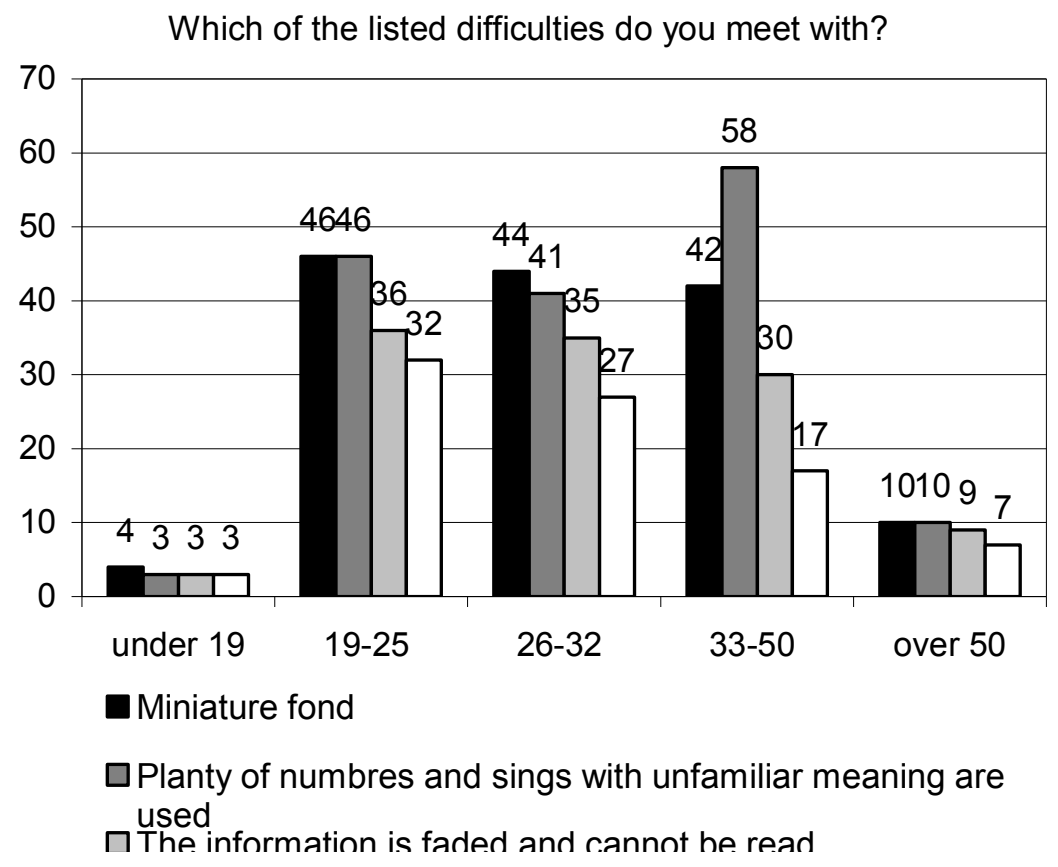

Figure 2. Which of the listed difficulties do you meet with?

Gracia A. and Tiziana de magistris (2016) measured the importance consumers attach to differend labeling schemes aviaible in the food market. The results show that people most preferred labeling shame was the PDO indication, EU organic logo and closely followed by the nutritional fact panel [13].

The answers "yes" to the question: "What information while reading the packaging is not clear even when reading easily?" are shown in Figure 3. Based on the presented results we can conclude that in all age groups, symbols and signs are what is at least understandable and clear. It can also be concluded that the designation "E" on the product packaging for most of the respondents is a problem, because they do not know the exact meaning of this mark. The Agency for Food and Veterinary of Republic of Macedonia has developed a brochure [14] in order to inform the consumers about the significance of the designation "E" and thus to eliminate the above mentioned problem. The "E" followed by a number, on the packaging of food products indicates the presence of a certain additive. Each additive is a chemical compound whose formula is well known. In the European countries is used Exxx mark, while in countries outside of Europe for is used numerous tag for the appropriate additive. The colors were marked with $\mathrm{E}$ and series number from 100 , preservatives are marked with $\mathrm{E}$ and series number from 200 and antioxidants with $\mathrm{E}$ and the series number from 300, emulsifiers, thickening agencies with $E$ and series number from 400, taste amplifiers with $\mathrm{E}$ and series number from 600, anti-foaming, sweeteners are marked with E and series number from 900, except E420 and E421 (sorbitol and mannitol). 
Petrova et al. (2014) make analys in Bulgaria food labels. Results show that the $30 \%$ of costumers respondet that the most unclear information is about additives in the produtct which are marked whid the letter $\mathrm{E}$ and a number that specifies the type of additive [15].

The official advices for consumers provided by the Organization of Consumers and The Agency for Food and Veterinary, are that with diverse and moderate diet there are no possibilities for people to ingest food additives more than the accepted daily amounts [11, 16].

\section{What information while reading the packaging is not clear even} when reading easily?

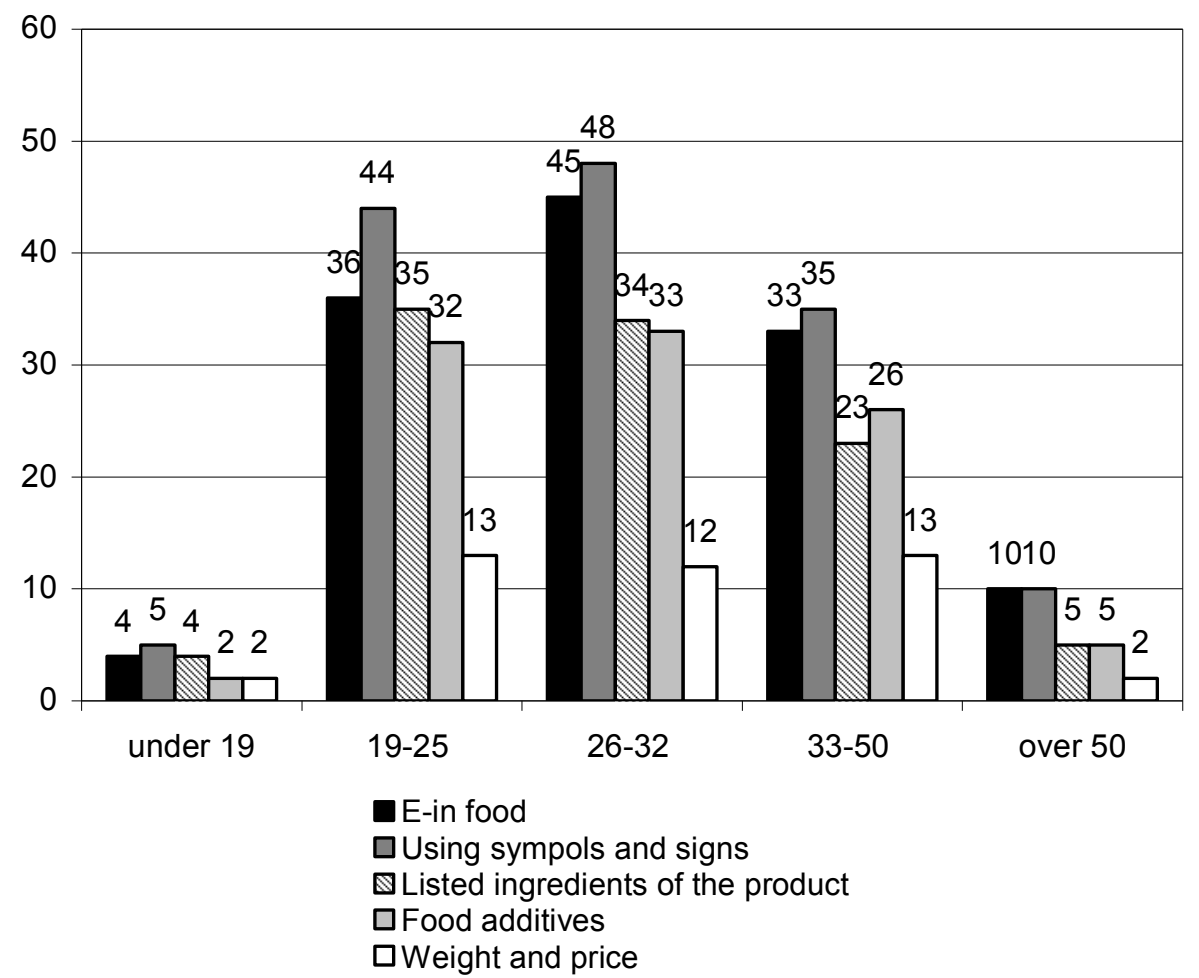

Figure 3. What information while reading the packaging is not clear even when reading easily?

During classification of the information given on the packing of the food products in the questionnaire, there were offered the following answers: duration, price, manufacturer, quantity, country of origin, information quality, information on accessories, preparation, energy and content of salt. The answers of the respondents are shown in Figure 4. The most important information is numbered with 1 , while the most irrelevant with 10 . 

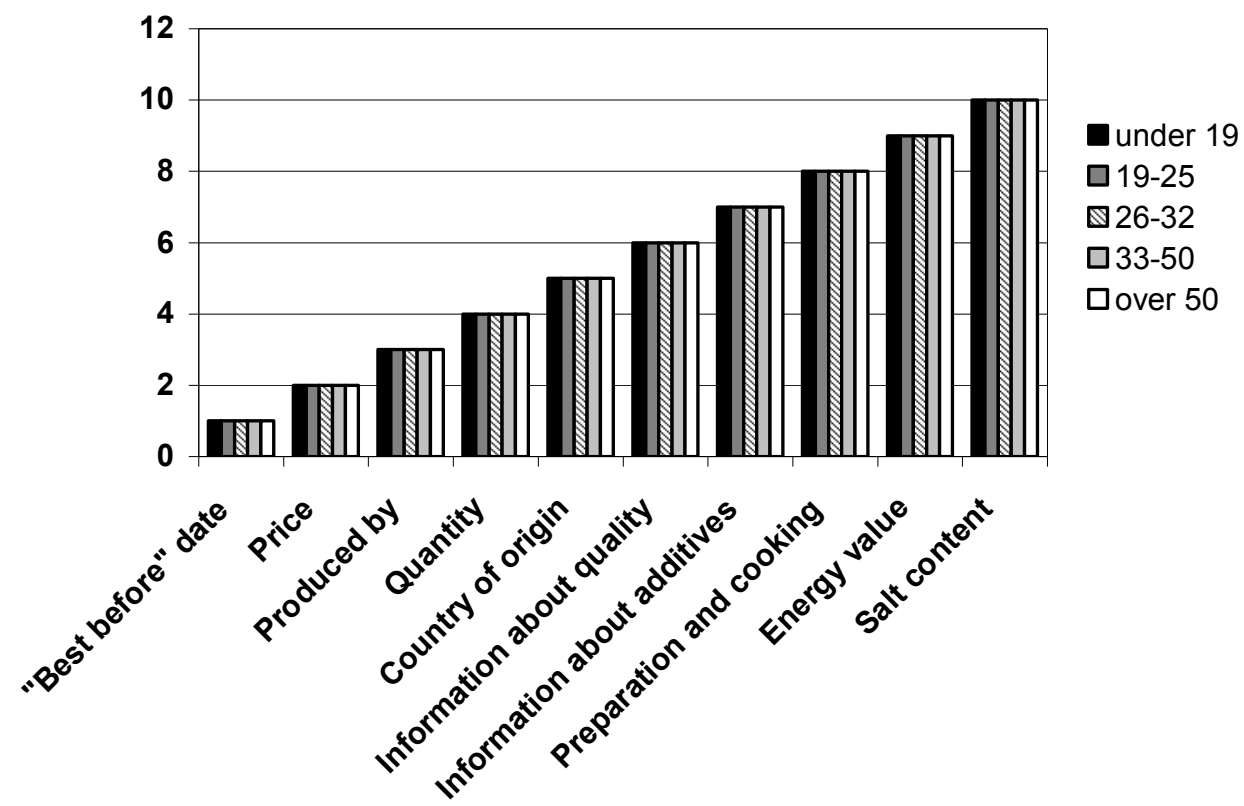

Figure 4. Classification of the information given to the packing

The Figure 4 shows that in all age groups the most important information is the shelf life, then the price, the manufacturer, the quantity, country of origin of the product, quality information, information about existing supplements, method of preparation, energy and content of salts. For all respondents is important the food product not to be with expired shelf life, because the consumption of such food products could cause some disorders. Also, the price of the product has a great influence in the choice of food products that would be purchased, due to the low purchasing power of the citizens of Republic of Macedonia.

By the respondents, as the least important information is evaluated the salt content in the food products (graded with 10), which is due to not informed consumers about the importance of salt content in the food products.

As for the energy value of the food products, in the future we expect that the information about the energy value of the products will be one of the determining factors when choosing a product that will be consumed, because most of the population in the Republic of Macedonia has become increasingly aware of the impact of the energy value of the products on health.

The Figure 5 shows the "Yes" answers to the question "What information do you think should be obligatory on the packaging of the food products?". 
Classification of the information given to the packing

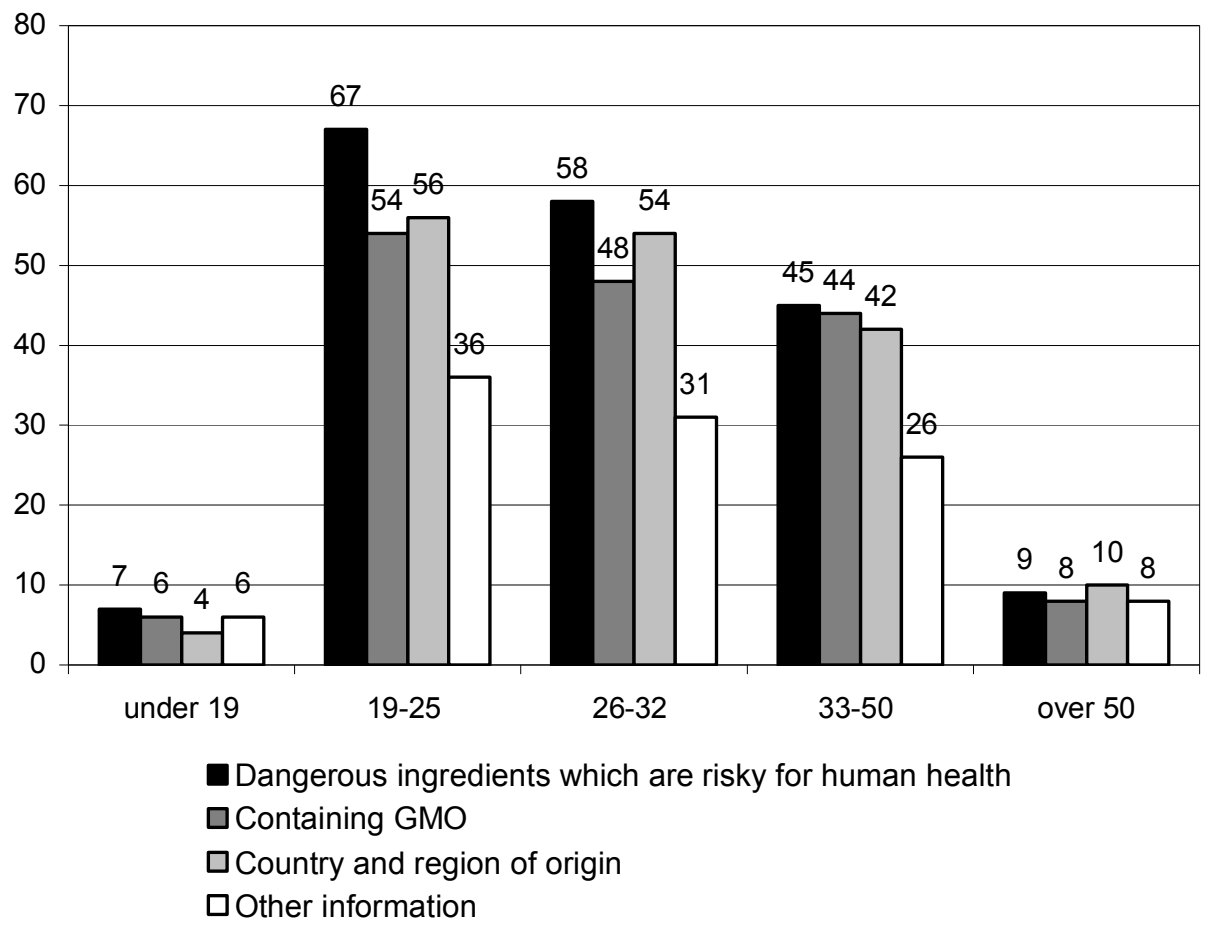

Figure 5. What information do you think should be obligatory on the packaging of the food products?

In all the groups of respondents, with most "Yes" answers were stated the dangerous components that pose a risk to human health. According to the responses, it can be concluded that the majority of respondents regardless of age believe that on the packaging should be mandatory information of dangerous components risky for the human health.

From the suggested changes that might be made on the packaging of the food products (Figure 6), respondents in all age groups (except in the group of 19-25 years) believe that on the labels should be put information about what group of spending products are intended. According to the respondents in the age group of 19-25 years on the packaging should be noted for whom the products are NOT intended (with "Yes" replied 59 out of 71 respondents). 
Which of the suggested changes on the packaging of the food products, you offer to make for a more pleasant shopping?

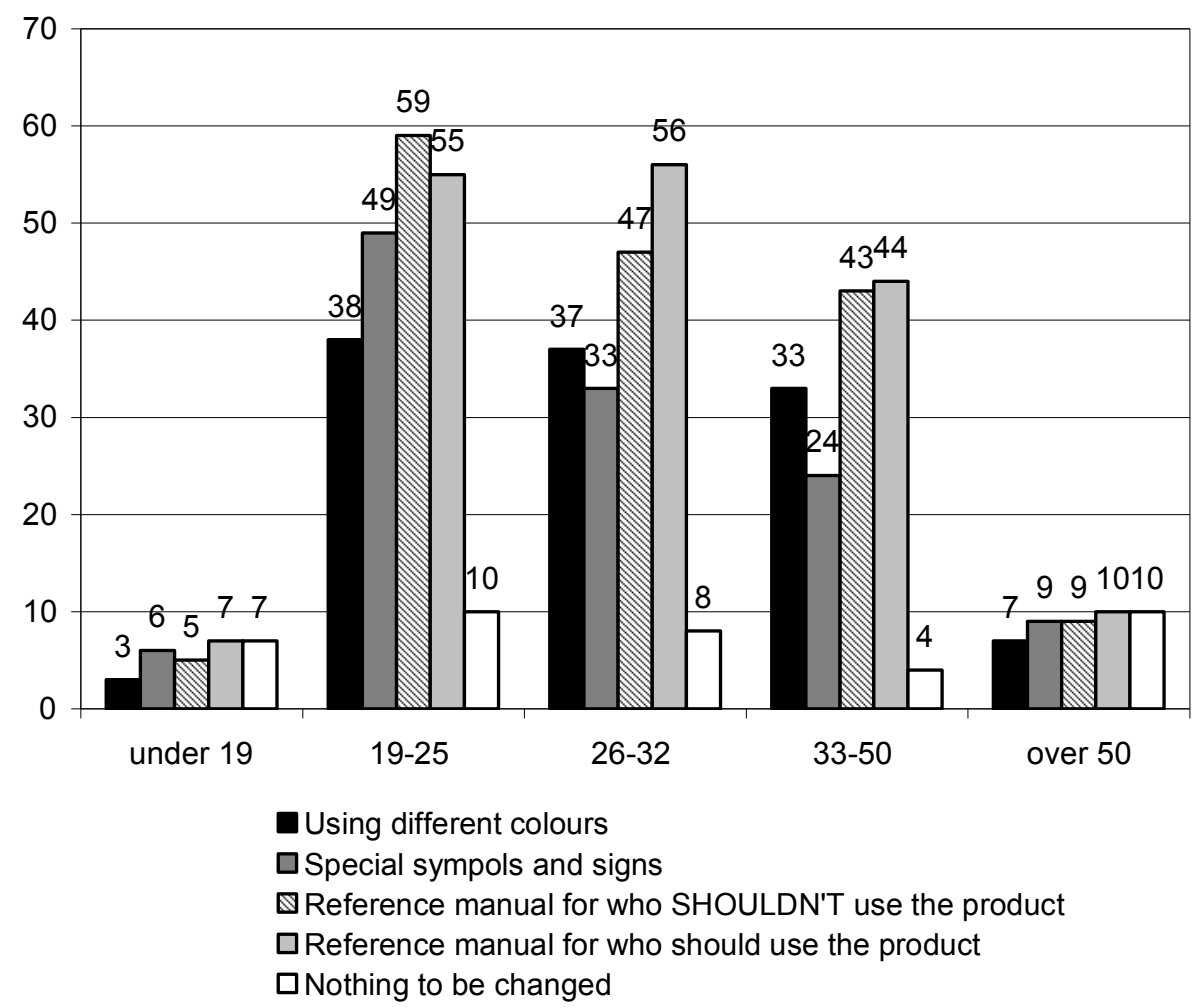

Figure 6. Which of the suggested changes on the packaging of the food products, you offer to make for a more pleasant shopping?

According to the Regulation on labeling the food products as additional and useful information that can be found on the product are: telephone number of the manufacturer, the trade name of the product if the manufacturer has, importer or distributor for additional information's, product handling, storage, delay, recycling and similar [9].

\section{Conclusion}

Based on the results of the survey, it can be concluded that consumers when choosing a food product they want to buy most often read the label with which the products are marked. From the problems they face when reading labels it should be indicated the small fund and the use of many figures and signs of unknown importance as well as marked "E". During classification of what is important when choosing a food product in the first place is the shelf life, and then the cost of the product. Respondents, regardless of age, consider mandatory that on the packaging should be an information about the presence of dangerous components that could cause certain disorders in human healthcare. For respondents of 
great importance is the existence on the product of an information for which group are those products intended to be spend.

To eliminate the problems mentioned by the consumers in the future it should be increased the control of food producers, as they respect the stipulated rules and regulations set out in the Law on Food Safety of the Republic of of Macedonia, the Rulebook on food labeling and Guidelines of good practice for food operators regarding the new EU requirements for food labeling.

At the same time it is important to increase the awareness of the consumers about the importance of numbers, symbols and labels, which they meet on the labeling of food products. It should be emphasized that the Agency for Food and Veterinary of the Republic of Macedonia in cooperation with the Organization of consumers for a long time undertake a lot of activities for education and information the consumers about labeling of certain food products by placing in public a number of brochures (Food additives and consumer, Food supplements, Foods for particular nutritional uses, etc.), guides and leaflets (Guide to consumers through the law on food safety, How to read the labeling of foodstuffs, What information should include labeling of food? labeling misleading, leaflets relating to labeling of meat, dairy and processed fish, leaflets relating to labeling of foods for infants and young children, food intended for diet and nutrition for athletes and others).

\section{References}

1. Bandara B.E.S., De Silva D.A.M., Maduwanthi B.C.H., Warunasinghe W.A.A.I. (2016), Impact of food labeling information on consumer purchasing decision: with special reference to faculty of Agricultural Sciences, Procedia Food Science, 6, pp. 309-313.

2. Mnerie D., Vasile Mnerie A., Birca A., Deacua A. (2015), Integrated System of the Population`s Education of the Foodstuffs`Nutritional Labeling, Procedia - Social and Behavioral Sciences, 191, pp. 1361-1366.

3. Soederberg Miller Lisa M., Cassady L.. D. (2015), The effects of nutrition knowledge on food label use. A review of the literature, Appetite, 92, pp. 207-216.

4. Talagala A.I., Arambepola C. (2016), Use of food labels by adolescents to make healthier choices on snacks: A cross-sectional study from Sri Lanka, BMC Public Health, 16(1).

5. Georgescu C., Birca A., Mironescu M., Tita A. M., Shamtsyan M., Mironescu D.I., Tita O. (2016), Consumer perceptions of nutrition and health claims from food labels in Romania, Journal of Hygienic Engineering and Design, pp. 13-18.

6. (2011), Law on Food Safety of the Republic of Macedonia, Official Gazette of RM br. 157 / 2010, Guide to consumers through the law on food safety.

7. Sadílek T. (2016), System of quality labels in the European Union, Ukrainian Food Journal, 5(3), pp. 579-587.

8. Dumitru Mnerie, Liviu Gaceu, Oleksii Gubenia, Mark Shamtsyan, Adriana Birca, Gabriela Victoria Mnerie (2016), Comparative study on the evolution of the food labeling quality in some countries from the Black Sea region, Journal of Hygienic Engineering and Design, 14, pp. 60-65.

9. Rulebook on food labeling, Official Gazette of RM br.118/05. 
10. Guidance on good practice for food operators in terms of the new EU requirements for food labeling (2014), Agency for Food and Veterinary of the Republic of Macedonia, Skopje.

11. Agency for Food and Veterinary of the Republic of Macedonia, Available at http://www.fva.gov.mk

12. Alibabić V., Mujić I., Rudić D., Bajramović M., Jokić S., Šertović E., Ružnić A. (2012), Labeling of food products on the B\&H market and consumer behavior towards nutrition and health information of the product, Procedia - Social and Behavioral Sciences, 46, pp. 973-979.

13. Gracia A., de Magistris T. (2016), Consumer preferences for food labeling: What ranks first?, Food Control, 61, pp. 39-46.

14. Agency for Food and Veterinary of the Republic of Macedonia (2011), Food additives and consumers - brochure, Skopje.

15. Petorva M., Kostova I., Ivanova N., Ivanova I., Damyanova S. (2014), Food Labels An Opportunity for informed choice of Food, Proceeding of BIOATLAS 2014 Conference, pp. 96-102.

16. Organization of Consumers of Macedonia, Available at: www.opm.org.mk. 